\title{
Hormone replacement therapy and survival after surgery for ovarian cancer
}

\author{
R A Eeles, S Tan, E Wiltshaw, I Fryatt, R P A'Hern, J H Shepherd, C L Harmer, P R Blake, \\ C E D Chilvers
}

\begin{abstract}
Objective-To evaluate whether hormone replacement therapy affects survival in women who have undergone bilateral salpingo-oophorectomy because of epithelial ovarian cancer.

Design-Retrospective analysis by review of patients' notes and questionnaires completed by general practitioners to compare the overall survival and disease free survival in patients with ovarian cancer who did or did not receive hormone replacement therapy after diagnosis. Data were analysed by Cox regression, with hormone replacement therapy as a time dependent covariate because patients who received hormone replacement did so at different times after diagnosis.
\end{abstract}

Setting-Gynaecological oncology unit of Royal Marsden Hospital.

Patients -373 patients aged 50 years or younger who attended the hospital from 1972 to 1988 . All of the women had undergone bilateral salpingooophorectomy for epithelial ovarian cancer. In all, 78 had received hormone replacement therapy, starting at a median of four months after diagnosis.

Intervention-A questionnaire was sent to the general practitioners of all patients who were not recorded as having received hormone replacement therapy.

Main outcome measures-Overall survival and disease free survival.

Results-There was no significant difference in survival between women receiving hormone replacement therapy and those not receiving it after accounting for the effects of other known prognostic factors (stage of cancer, differentiation of tumour, histological results, and time to relapse). The relative risk of dying in those who received hormone replacement therapy was 0.73 (95\% confidence interval 0.44 to 1.20). In addition, there was no significant difference in disease free survival (relative risk in those receiving hormone replacement therapy was $0.90 ; 95 \%$ confidence interval 0.52 to 1.54 ).

Conclusions-This study shows that hormone replacement therapy is unlikely to have a detrimental effect on the prognosis of patients with ovarian cancer, but this would be shown conclusively only by a randomised controlled trial.

\section{Introduction}

In premenopausal women bilateral salpingooophorectomy, as part of the treatment for ovarian cancer, of necessity induces a premature menopause. As a result the attendant unpleasant short term symptoms of hot flushes and the long term risks of osteoporosis and ischaemic heart disease occur in long term survivors. ${ }^{1-3}$

Doctors have been reluctant to give patients with ovarian cancer hormone replacement therapy because of fears that it would decrease survival by increasing the chance of relapse: some ovarian cancer cells have oestrogen and progesterone receptors within the cytosol ${ }^{4}$ and some epidemiological studies have shown an increased risk of ovarian cancer in women who have received hormone replacement therapy. The overall evidence is, however, unclear, with relative risks ranging from 0.6 to $1 \cdot 6 .^{5-11}$ We conducted a retrospective study of women with epithelial ovarian cancer who were 50 years old or younger at the time of diagnosis to find out whether survival was compromised by hormone replacement therapy.

\section{Patients and methods}

Patients with epithelial ovarian cancer referred to our hospital between 1972 and 1988 were identified from the Hospital Activity Analysis database. For all cases included in the analysis the histological results were reviewed at the hospital.

The hospital notes and drug charts were reviewed for prescriptions for oral hormone replacement therapy. In addition, a questionnaire was sent to the general practitioners of all patients who were not recorded as having received hormone replacement therapy. The following details were noted: date of birth, date of diagnosis, date of presentation, stage of cancer at presentation (by International Federation of Gynaecology and Obstetrics staging), histological results, tumour differentiation, extent of initial surgery ("complete" surgery included omentectomy; all patients underwent bilateral salpingo-oophorectomy and total abdominal hysterectomy), date of relapse, current status (alive or dead), date last seen or date of death, cause of death if applicable, and whether or not a second tumour had developed.

If a patient had received oral hormone replacement therapy the type (oestrogens alone or progestogens alone, or both, or testosterone) was noted, as was the date of starting and the length of time the patient received hormone replacement.

The effect of hormone replacement therapy on overall survival and disease free survival was estimated by Cox regression ${ }^{12}$ to allow for possible differences between the distribution of prognostic factors in those receiving and those not receiving hormone replacement therapy. As hormone replacement is not prescribed immediately after oophorectomy in most patients there are difficulties in estimating its effect. There are two possible sources of bias in patients who do not start to receive the treatment until after the base time for the survival analysis (in this case base time was presentation at the hospital). Firstly, the effect, if any, will be present only after the date that hormone replacement therapy was first given. Secondly, patients have to survive long enough to develop menopausal symptoms

BMF 1991;302:259-62 
and ask for hormone replacement therapy; hence those who do not live long after diagnosis would tend not to have received it, and this would give a spurious positive survival effect for those receiving it. These problems also apply to the effect of relapse on survival. To overcome any bias due to these sources of error we applied two different methods of survival analysis by Cox regression to the data. The first was the classical landmark method and the second was the use of time dependent covariates.

\section{LANDMARK METHOD}

This method uses an arbitrary point in time (in this case one year) after the base time of the analysis and considers only patients who are not censored (lost to follow up) and do not die before that time. ${ }^{13}$ Patients receiving hormone replacement therapy or who have relapsed are considered to be in the hormone replacement therapy group or relapse group only if they start receiving hormone replacement or relapse before the arbitrary time point. Any patients who start to receive hormone replacement after one year are grouped as not receiving hormone replacement therapy. By using stage of cancer, differentiation of tumour, completeness of surgery, presence of progressive disease or relapse within the first year, and receiving hormone replacement therapy within the first year as covariates in the $2 \mathrm{~L}$ program from the biomedical data package the relative risk for each covariate was calculated. With these relative risks two survival curves were plotted, assuming that the stage of cancer, histological results, tumour differentiation distributions, and proportion of patients with complete surgery and progressive disease were the same in both groups - that is, in those prescribed hormone replacement therapy in the first year and those not prescribed it in the first year.

TABLE I-Time from diagnosis to start of hormone replacement therapy in patients who had undergone surgery for ovarian cancer

\begin{tabular}{lccccccccc}
\hline Time before treatment (months) & $\leqslant 6$ & -12 & -18 & -24 & -30 & -36 & -42 & -48 & $>49$ \\
No of patients & 46 & 8 & 5 & 5 & 3 & 3 & 4 & & 4 \\
\hline
\end{tabular}

TABLE II-Length of time that patients who had undergone surgery for ovarian cancer received hormone replacement therapy

\begin{tabular}{llllllllllllr}
\hline $\begin{array}{l}\text { Time receiving hormone replacement } \\
\text { (years) }\end{array}$ & $\leqslant 1$ & -2 & -3 & -4 & -5 & -6 & -7 & -8 & -9 & -10 & -11 & -12 \\
No of patients & 21 & 12 & 15 & 6 & 5 & 2 & 4 & & 2 & 5 & 12 & 5
\end{tabular}

TABLE III-Characteristics of patients who had undergone surgery for ovarian cancer, who were or were not receiving hormone replacement therapy. Figures are numbers (percentages) of patients

\begin{tabular}{|c|c|c|c|}
\hline & $\begin{array}{l}\text { Those receiving hormone } \\
\text { replacement }(\mathrm{n}=78)\end{array}$ & $\begin{array}{c}\text { Those not receiving } \\
\text { hormone replacement } \\
(n=295)\end{array}$ & Significance \\
\hline \multicolumn{4}{|l|}{ Age (years): } \\
\hline$<20$ & l(1) & $1(<1)$ & $\chi^{2}=11 \cdot 74^{\star}$ \\
\hline $20-29$ & $11(14)$ & $29(10)$ & $\hat{p}=0.001$ \\
\hline $30-39$ & $26(33)$ & $46(16)$ & \\
\hline $40-49$ & $40(52)$ & $207(70)$ & \\
\hline 50 & & $12(4)$ & \\
\hline \multicolumn{4}{|l|}{ Stage of cancer: } \\
\hline I & $33(42)$ & $87(30)$ & $\chi^{2}=2 \cdot 58^{\star}$ \\
\hline II & $10(13)$ & $52(18)$ & $\mathrm{p}=0 \cdot 11$ \\
\hline III & $27(35)$ & $122(40)$ & \\
\hline IV & $8(10)$ & $34(12)$ & \\
\hline \multicolumn{4}{|c|}{ Histological appearance of tumour: } \\
\hline Serous & $26(33)$ & $111(38)$ & $\chi^{2}=3.55 t$ \\
\hline Mucinous & $23(30)$ & $64(22)$ & $\mathrm{p}=0.47$ \\
\hline Endometrioid & $11(14)$ & $34(11)$ & \\
\hline Adenocarcinoma & $14(18)$ & $73(25)$ & \\
\hline Clear cell & $4(5)$ & $13(4)$ & \\
\hline \multicolumn{4}{|l|}{ Differentiation of tumour: } \\
\hline Well differentiated & $20(26)$ & $42(14)$ & $\gamma^{2}=6 \cdot 73^{\star}$ \\
\hline Moderate & $18(22)$ & $64(22)$ & $\dot{\mathrm{p}}=0.009$ \\
\hline Poor & $20(26)$ & $111(38)$ & \\
\hline Unspecified & $20(26)$ & $78(26)$ & \\
\hline \multicolumn{4}{|l|}{ Surgery: } \\
\hline Complete (omentectomy) & $23(30)$ & $82(28)$ & $\chi^{2}=0 \cdot 02^{\star}$ \\
\hline No omentectomy & $55(70)$ & $213(72)$ & $\mathrm{p}=0.88$ \\
\hline
\end{tabular}

$\star \chi^{2}$ Test for trend, $\mathrm{df}=1$.

$+\chi^{2}$ Test for heterogeneity, $\mathrm{df}=4$.
TIME DEPENDENT COVARIATE METHOD

By this method ${ }^{14}$ patients receiving hormone replacement therapy after base time were included in the group not receiving hormone replacement up to the time at which hormone replacement was given, and patients who had a relapse after base time were included in the group who did not have a relapse until the time of relapse. This method therefore more realistically takes into account the fact that patients received hormone replacement therapy at different times from the date of diagnosis. This analysis was also performed with the $2 \mathrm{~L}$ program of the biomedical data package.

The relative risk for each known prognostic factor was calculated first, assuming that, except for recurrence, the worst prognostic factor within each group of factors had a relative risk of $1.00-$ that is, a relative risk of $<1.00$ conferred a survival benefit Recurrence was analysed as a time dependent covariate with no recurrence having a relative risk of $1 \cdot 00$. Thus time to relapse was added to the other prognostic factors as a time dependent covariate before the use of hormone replacement therapy was finally added to the analysis.

\section{Results}

In all, 408 patients with epithelial ovarian cancer were identified from the hospital database. Thirty five patients were excluded, 22 of these because histological examination showed non-epithelial abnormalities when reviewed (teratoma or sex cord tumour in 16 patients, non-ovarian primary tumour in three, borderline histological appearances in one patient, benign histological appearances in one, and no histological results were available for review in one patient). Two patients had had breast cancer diagnosed previously and were also excluded. The remaining 11 patients were excluded because they still had one ovary after surgery. This left 373 patients for analysis. Seventy eight patients had received oral hormone replacement therapy: 65 were given the treatment at hospital outpatient visits, and 13 had been started on hormone replacement therapy by their general practitioner or gynaecologist, as ascertained from the general practitioner questionnaires. Of the 308 general practitioners who were sent questionnaires, 150 replied (49\%). We assumed that of those patients whose general practitioners did not reply no more than 13 would have received hormone replacement therapy and this would not compromise the analysis. These patients were therefore assumed not to have received hormone replacement therapy.

Of the 78 patients known to be receiving hormone replacement therapy, 32 received oestrogen alone (Premarin $0.625 \mathrm{mg}$ ), 38 received oestrogen plus progestogen (Prempak-C, which was Premarin $0.625 \mathrm{mg}$ and norgestrel $0.5 \mathrm{mg}$ in all cases), six received progestogens alone, and two received testosterone. The median time to starting hormone replacement therapy was 135 days (range $0-4845$ days), and 74 patients $(95 \%)$ had started hormone replacement therapy within 1185 days (three years and three months) after diagnosis (table I). Table II gives the length of time patients were receiving the treatment. In all, $17(22 \%)$ had received hormone replacement for more than six years. The median time for receiving treatment was 28 months (range $<1-200$ months). The median follow up was 42 months (range $<1$ month to 18 years).

Table III gives the patients' characteristics. The group receiving hormone replacement therapy comprised a slightly higher percentage of younger patients $\left(\chi^{2}\right.$ trend $\left.=11 \cdot 74, \mathrm{p}=0.001\right)$, patients with early stage disease $\left(\chi^{2}\right.$ trend $\left.=2.58, p=0.11\right)$, and 
those with well differentiated tumours $\left(\chi^{2}\right.$ trend $=$ $6.73, p=0.009)$ compared with those in the group of patients not receiving hormone replacement. There were no appreciable differences in the proportion of patients with different histological results or types of surgery between the two groups. When survival was analysed for the whole group the known prognostic factors of stage of disease, differentiation of tumour, histological results, ${ }^{15}$ and relapse were found to be significant.

For the landmark method of analysis 272 patients were not censored in the first 12 months and survived beyond the first 12 months. Of these, 42 received hormone replacement therapy in that initial year. The relative risk of death in those in the hormone replacement therapy arm compared with those in the arm comprising people not receiving hormone replacement therapy was 0.63 (95\% confidence interval 0.30 to 1.34). The figure gives the results. The upper curve corresponds to the survival of the 42 patients who survived to 12 months and had received hormone replacement therapy by that time. The lower curve is the survival that we predict these patients would have had if they had not received hormone replacement.

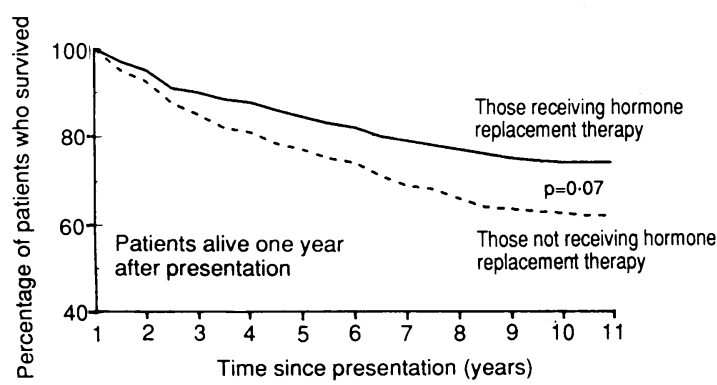

Percentage survival in patients who had undergone surgery for ovarian cancer who received hormone replacement therapy within a year $v$ corrected percentage survival if these patients had not received hormone replacement within a year according to time since presentation at hospital

Table IV gives the results of the time dependent analysis. As expected, patients with later stage cancers, clear cells, and undifferentiated appearances on histology, poorly differentiated tumours, and relapse of their disease did less well. After correcting for all these factors the relative risk of death when patients received hormone replacement therapy was $0.73(95 \%$ confidence interval $0 \cdot 44$ to $1 \cdot 20$ ).

TABLE IV-Time dependent analysis of survival in patients who had undergone surgery for ovarian cancer who were or were not receiving hormone replacement therapy

\begin{tabular}{|c|c|c|}
\hline & Relative risk & $\begin{array}{l}95 \% \text { Confidence } \\
\text { interval }\end{array}$ \\
\hline \multicolumn{3}{|l|}{ Stage of cancer: } \\
\hline I & $0 \cdot 15$ & 0.08 to 0.25 \\
\hline IIA plus IIB & $0 \cdot 11$ & 0.06 to 0.22 \\
\hline IIC & $0 \cdot 21$ & 0.09 to 0.50 \\
\hline IIIA plus IIIB & 0.51 & 0.35 to 0.76 \\
\hline IIIC plus IV & $1 \cdot 00$ & \\
\hline \multicolumn{3}{|c|}{ Histological appearance of tumour: } \\
\hline Serous & & \\
\hline Mucinous & 0.44 & 0.31 to 0.62 \\
\hline Endometrioid & & \\
\hline $\begin{array}{l}\text { Clear cell } \\
\quad \text { adenocarcinoma }\end{array}$ & $1 \cdot 00$ & \\
\hline \multicolumn{3}{|c|}{ Differentiation of tumour: } \\
\hline Well differentiated & $0 \cdot 38$ & $0 \cdot 20$ to $0 \cdot 74$ \\
\hline Moderate/poor & $1 \cdot 00$ & \\
\hline Recurrence*: & & \\
\hline Yes & $7 \cdot 97$ & $4 \cdot 80$ to $13 \cdot 2$ \\
\hline No & 1.00 & \\
\hline \multicolumn{3}{|c|}{ Hormone replacement therapyt: } \\
\hline Yes & $0 \cdot 73$ & 0.44 to 1.20 \\
\hline No & 1.00 & \\
\hline
\end{tabular}

* If time to relapse is removed from analysis (analysed as a time dependent covariate) relative risk $=0.66(95 \%$ confidence interval $0 \cdot 40$ to $1 \cdot 10)$.

†Time to relapse and time to start of hormone replacement therapy were added as time dependent variables.
Disease free survival was similarly analysed, and the relative risk of relapse when hormone replacement therapy was given was $0.90(0.52$ to 1.54$)$ when corrected for the other prognostic factors. Forty four patients had to be excluded from this analysis because they either had a relapse before presentation or had progressive disease - that is, they never had a response and therefore could not have a date of relapse.

A total of 164 patients died (17 of the 78 who received hormone replacement therapy and 147 of the 295 who did not). All deaths were of ovarian cancer except two: one patient died of a cerebrovascular accident (she had not received hormone replacement), and the other patient died of septicaemia after treatment with high dose cyclophosphamide.

There were seven patients with secondary primary cancers: three with breast cancers, one with squamous cell carcinoma and one with basal cell carcinoma of the skin, one with carcinoma of the cervix, and one with malignant schwannoma of the forearm. None had received hormone replacement.

Although numbers were small, hormone replacement therapy improved the survival of patients with endometrioid cancer and those with clear cell ovarian cancer. The numbers of women receiving oestrogen alone and combined oestrogen and progestogen were 32 and 38 respectively. When the two groups were compared there was no apparent difference in the effect of the two types of hormonal treatment on survival, but only a very large effect would be detected with such small numbers.

\section{Discussion}

Hormone replacement therapy is effective in alleviating the unpleasant vasomotor symptoms of the menopause, ${ }^{16}$ and longer treatment prevents osteoporosis. ${ }^{17}$ The side effects of the premature menopause induced by surgery in patients with ovarian cancer can also be relieved by hormone replacement therapy.

We analysed data collected retrospectively by two methods to allow for potential bias; both give similar results.

In the time dependent analysis (table IV) the time to relapse was added to the other prognostic factors as a time dependent covariate before adding the presence or absence of hormone replacement therapy to the analysis. This could possibly have altered the final result because patients who had undergone a relapse may not have been given hormone replacement therapy. In fact, 12 of the 78 patients who received hormone replacement did so after their first relapse. When the date of relapse was removed from the analysis the relative risk in patients given hormone replacement therapy lowered slightly but not appreciably ( 0.66 compared with 0.73$)$.

The estimated effect of hormone replacement therapy would therefore be a $27 \%$ reduction in mortality. However, as the $95 \%$ confidence intervals include unity no effect or even a small harmful effect cannot be ruled out. It is unlikely that hormone replacement therapy is extremely detrimental to survival as the upper confidence limit is $1 \cdot 20$. Also, there was no apparent effect of hormone replacement on disease free survival, although the confidence intervals again are wide. There is thus no evidence from this study that would indicate that patients who have had a hysterectomy and bilateral salpingooophorectomy for carcinoma of the ovary should be denied hormone replacement therapy. This is particularly important in women aged 50 years or younger at the time of diagnosis as these women, if they survive their ovarian cancer, will live long enough to develop osteoporosis caused by a premature 
menopause.: Such patients constitute $24 \%$ of all those with ovarian cancer seen at our centre. The other group to whom this applies is women with stage I disease, who have an overall five year survival of $61 \%{ }^{15}$ and a five year survival of $88 \%$ when aged 50 or under at diagnosis (figures obtained from our hospital).

In this study roughly equal numbers of women were treated with oestrogen plus progestogen as with unopposed oestrogen. Hormone replacement therapy with oestrogen alone has been associated with an increased risk of endometrial cancers but is to be preferred to combination therapy for women who have had a hysterectomy. ${ }^{18}$ Henderson et al estimated that the overall benefit of unopposed oestrogen compared with oestrogen plus progestogen in such women is substantial in terms of a greater reduction in the incidence of ischaemic heart disease, with only a marginal loss of benefit in terms of hip fractures due to osteoporosis. ${ }^{19}$ The relative effects on the breast are, however, at present unclear. ${ }^{80}$

In conclusion, there is no evidence from our study that hormone replacement therapy is detrimental to disease free survival and overall survival in patients with ovarian cancer. Whether there is a beneficial effect would have to be investigated in a large randomised controlled trial, and one is currently being proposed. Meanwhile, hormone replacement therapy in these patients will substantially improve their quality of life, particularly in those who prove to be long term survivors.

We thank the following for their help in finding case notes: J Matthews, S Jones, J Doherty, A Greenidge, and A Mott. We also thank all the general practitioners who returned questionnaires and showed such an enthusiastic interest in this study.
1 Cummings SR, Kelsey JL, Nevitt MC, O'Dowd KJ. Epidemiology of osteoporosis and osteoporotic fractures. Epidemiol Rev 1985;7:178-208.

2 Richelson LS, Wahner HW, Melton LJ, Riggs BL. Relative contributions of aging and estrogen deficiency to postmenopausal bone loss. $N \mathrm{Engl} f \mathrm{Med}$ 1984;311:1273-5.

3 Colditz GA, Willett WC, Stampfer MJ, Rosner B, Speizer FE, Henneken $\mathrm{CH}$. Menopause and the risk of coronary heart disease in women. $N$ Engl f CH. Menopause and the
Med 1987;316:1105-10.

4 Kuhnel R, Delemarre JFM, Rao BR, Stolk JG. Correlation of multiple steroid receptors with histological type and grade in human ovarian cancer. Int $\mathcal{f}$ Gynecol Pathol 1987;6:248-56.

5 Hartge P, Hoover R, McGowan L, Lesher L, Norris HJ. Menopause and ovarian cancer. Am $\mathcal{F}$ Epidemiol 1988;127:990-8.

6 Hildreth NG, Kelsey JL, LiVolsi VA, et al. An epidemiologic study of epithelial carcinoma of the ovary. Am f Epidemiol 1981;114:398-405.

La Vecchia C, Liberati A, Franceschi S. Noncontraceptive estrogen use and the occurrence of ovarian cancer. $\mathcal{F N C I}$ 1982;69:1207.

8 Hunt K, Vessey M, McPherson K, Coleman M. Long term surveillance of mortality and cancer incidence in women receiving hormone replacement therapy. Br f Obstet Gynaecol 1987;94:620-35.

9 Weiss NS, Lyon JL, Krishnamurthy S, Dietert SE, Liff JM, Daling JR. Noncontraceptive estrogen use and the occurrence of ovarian cancer. INCI 1982;68:95-8.

10 Cramer DW, Hutchison GB, Welch WR, Scully RE, Ryan KJ. Determinants of ovarian cancer risk. I. Reproductive experiences and family history. fNCI 1983;71:711-6.

11 Tzonou A, Day NE, Trichopoulos D, et al. The epidemiology of ovarian cancer in Greece: a case control study. Eur $\mathcal{F}$ Cancer Clin Oncol 1984;20: 1045-52.

12 Cox DR. Regression models and life-tables. fournal of the Royal Statistical Society [Series B] 1972;34:187-200.

13 Anderson JR, Cain KC, Gelber RD, Gelman RS. Analysis and interpretation of the comparison of survival by treatment outcome variables in cancer clinical trials. Cancer Treatment Reports 1985;69:1139-44.

4 Kalbfleisch JD, Prentice RL. The statistical analysis of failure time data. New York: Wiley, 1980

15 Tobias JS, Griffiths CT. Management of ovarian carcinoma: current concepts and future prospects. $N$ Engl F Med 1976;294:818-23.

16 Coope J, Thomson JM, Poller L. Effects of "natural oestrogen" replacemen therapy on menopausal symptoms and blood clotting. BMF 1975;4:139-43.

17 Horsman A, Gallagher JC, Simpson M, Nordin BEC. Prospective trial of oestrogen and calcium in postmenopausal women. BMF 1977;ii:789-92.

18 Whitehead $M$, Lobo RA. Progestogen use in postmenopausal women. Lancet 1988;ii: $1243-4$.

19 Henderson BE, Pike MC, Ross RK, Mack TM, Lobo RA. Re-evaluating the role of progestogen therapy after the menopause. Fertil Steril 1988;49:9-15S 20 Barrett-Connor E. Postmenopausal oestrogen replacement and breast cancer. N Engl F Med 1989;321:319-20.

(Accepted 21 November 1990)
Department of Thoracic

Medicine, Ipswich

Hospital, Ipswich IP4 5PD,

Suffolk

Douglas Seaton, $M D$

consultant physician

Kathir Yoganathan, MRCP,

medical registrar

Thomas Coady, $\mathrm{MB}$,

associate specialist

Richard Barker, MRCP,

medical registrar

Correspondence to:

Dr Seaton.

BMF 1991;302:262-5

\section{Spontaneous pneumothorax: marker gas technique for predicting outcome of manual aspiration}

\author{
Douglas Seaton, Kathir Yoganathan, Thomas Coady, Richard Barker
}

Abstract

Objective-To determine whether in a patient with spontaneous pneumothorax the presence or absence of a pleural leak can be shown at the time of manual aspiration by use of a marker gas. Also, to find out if the technique can predict whether manual aspiration will be successful, hence avoiding the need for intercostal tube drainage.

Design-Prospective study of 25 episodes of pneumothorax during which patients breathed air from a Douglas bag that contained chlorofluorocarbon gases from a metered dose inhaler while the pneumothorax was aspirated.

Setting-Medical unit of a district general hospital.

Patients - 22 patients who presented over nine months with acute pneumothorax.

Main outcome measures-Presence or absence of chlorofluorocarbon marker gases in the aspirate. Presence or absence of sustained re-expansion of the affected lung in the chest radiograph.

Results-Marker gas was detected in the aspirate from 16 out of 25 pneumothoraces. Of these, 13 required intercostal tube drainage because of failure of the the lung to re-expand. Marker gas was not detected in nine cases, and in all of these cases manual aspiration resulted in sustained re-expansion of the lung.

Conclusions-The presence or absence of a pleural leak during manual aspiration of spontaneous pneumothorax can be shown by using this technique. The absence of marker gas in the aspirate implies that manual aspiration will be successful, whereas its presence predicts, in most cases, either failure of manual aspiration to expand the lung or early recollapse of the lung.

\section{Introduction}

Spontaneous pneumothorax is usually treated actively with an intercostal tube and underwater seal drain on the grounds of size or if there is underlying lung disease. ${ }^{1}$ Simple manual aspiration is an alternative procedure that spares the patient discomfort and is easier to perform. ${ }^{2.5} \mathrm{~A}$ disadvantage of aspiration is that it has been impossible to predict which lungs will recollapse within the next 24 hours as a result of a small persisting pleural leak. Such patients require further treatment, often with an intercostal drain, resulting in a longer hospital stay, whereas those in whom the pleural leak seals off spontaneously might benefit from simple aspiration and earlier discharge.

We have previously described a flame ionisation technique for detecting the chlorofluorocarbon propellants present in pressurised metered dose inhalers. ${ }^{6}$ We have now adapted this method to detect pleural leaks during manual aspiration of spontaneous 